\title{
A contribuição de F. C. Hoehne (1882-1959) para o pensamento agroambiental brasileiro
}

\author{
The contribution of F.C. Hoehne (1882-1959) for the Brazilian \\ agro-environmental thought
}

\author{
ARIEL DE ANDRADE MOLINA \\ Programa de Pós-graduação em Agronomia/Horticultura da Universidade Estadual Paulista | UNESP \\ LUIZ ANTONIO C. NORDER \\ Universidade Federal de São Carlos | UFSCar
}

RESUMO Na primeira metade do século XX, Frederico Carlos Hoehne (1882-1959) realizou um conjunto de pesquisas sobre Botânica e suas aplicações na agricultura tropical e atuou na formação e estruturação de algumas das mais importantes instituições científicas no Brasil, como o Instituto Butantã, o Museu do Ipiranga, o Instituto Biológico e o Instituto de Botânica. Além de ter sido um dos pioneiros da proteção florestal no Brasil, Hoehne procurou, através de uma expressiva produção bibliográfica, ampliar o conhecimento sobre as aplicações da Botânica e das espécies nativas, por exemplo, na agropecuária, na educação, na arborização urbana e de rodovias, no urbanismo e no paisagismo.

Palavras-Chave Frederico Carlos Hoehne - Botânica - História da Botânica

\begin{abstract}
In the first half of the 20th century, Frederico Carlos Hoehne (1882-1959) conducted several researches in Botany and its applications in tropical agriculture. He also worked on the establishment of some of the most important scientific institutions in Brazil, including Instituto Butantã, Museu do Ipiranga, Instituto Biológico and Instituto de Botânica. Considered one of the pioneers of forest protection in Brazil, Hoehne produced a significant bibliography aimed at disseminating and extending the knowledge about botany and indigenous species, for instance, in agricultural activities, education, urbanism and landscaping.
\end{abstract}

Key words Frederico Carlos Hoehne - Botany - History of Botany

\section{Introdução}

Boa parte das interpretações sobre a agricultura ecológica no Brasil identifica os movimentos agroambientais surgidos a partir da década de 1970 como parâmetro histórico de contestação à revolução verde e de concepção de outro modelo de agricultura. No entanto, há um conjunto de abordagens, estudos, pesquisas e eventos, realizados ao longo da primeira metade do século XX que, embora representem uma produção científica e cultural altamente relevante, são, atualmente, pouco conhecidos e, muitas vezes, desconsiderados nas análises atuais sobre a formação histórica do pensamento agroambiental brasileiro. 
Diversos estudos, desde os anos 1980, vêm evidenciando a importância dos espaços para a realização de atividades científicas em determinados contextos no período anterior aos anos 1930 no Brasil, época em que o sistema universitário era ainda pouco difundido e a formação de cientistas ocorria principalmente em instituições como o Museu Nacional e o Jardim Botânico no Rio de Janeiro, o Museu Paraense e o Museu Botânico do Amazonas, entre outras ${ }^{1}$. As análises sobre as instituições científicas, por sua vez, coincidem com a trajetória de seus diretores, tendo em vista que os cientistas com atuação destacada exerciam, simultaneamente, atividades de gestão e de produção intelectual ${ }^{2}$.

Nas primeiras décadas do século XX, como mostra Regina Horta Duarte, cientistas constituíram redes de cooperação, reconhecimento e amizade - e procuraram estabelecer múltiplas vinculações com a sociedade, através da realização de atividades culturais e educacionais, e com a esfera política, seja através de negociações para viabilização de seus projetos, ou da elaboração de conceitos, análises e propostas ${ }^{3}$. As instituições científicas em formação também se empenharam na constituição de projeto civilizador e de nacionalidade, em uma busca de interação com o pensamento social e com a cultura ${ }^{4}$. Para tanto, tornava-se central, entre outras ações, construir um conhecimento sobre 0 território, o que passou pela organização de grandes expedições pelas mais remotas regiões do país ${ }^{5}$. As considerações sobre história da ciência nos remetem às reflexões no campo da história ambiental, especialmente no que se refere aos processos sociais de construção do conhecimento sobre (a interação com) a natureza ${ }^{6}$.

Frederico Carlos Hoehne (1882-1959) é reconhecido como um dos pioneiros da defesa florestal no Brasil. José Luiz de Andrade Franco e José Augusto Drummond ressaltam sua importância para a formação de um pensamento social voltado para valorização da vegetação nativa e para criação de reservas florestais ${ }^{7}$. As publicações e atividades de Hoehne, no entanto, representam também uma notável contribuição para a caracterização de algumas das bases ecológicas de uma agricultura genuinamente brasileira.

Neste sentido, este texto analisa as interações entre agricultura e ambiente na obra de Frederico Carlos Hoehne, que atuou como pesquisador e chegou a receber o título de Doutor honoris causa em Filosofia pela Universidade de Goettingen (Alemanha), em meio a uma longa e notável trajetória de pesquisas em diversas áreas do conhecimento, com forte envolvimento em debates políticos no Brasil, especialmente, sobre organização das instituições de pesquisa científica, criação de reservas florestais, desenvolvimento agropecuário e indigenismo ${ }^{8}$. Analisa-se sua trajetória profissional, fortemente ligada à criação, estruturação e desenvolvimento de relevantes instituições científicas no Estado de São Paulo no campo da Botânica, com um foco para sua múltipla aplicação em contextos rurais e urbanos. Há ainda uma contextualização de suas incursões pela literatura infanto-juvenil e algumas de suas atividades políticas e culturais visando a divulgação de saberes botânicos e ambientais para o conjunto da sociedade.

\section{O início de carreira no Museu Nacional: Rio de Janeiro, 1907-1916}

Hoehne era filho de imigrantes alemães estabelecidos como pequenos agricultores em Juiz de Fora (MG). Em 1890, aos oito anos, recebera de seu pai uma orquídea do gênero Laelia como presente. Passou então, ainda muito jovem, a formar um pequeno orquidário em um pomar abandonado na propriedade da família. No ano seguinte, começou a frequentar uma escola que havia sido transformada em um colégio agrícola. Seus pais custeavam cerca de metade de sua manutenção na escola, o que era complementado pelo seu trabalho como limpador, copeiro, monitor e mensageiro. Hoehne concluiu sua formação no colégio agrícola em 1899, aos 17 anos. Encerrava-se ali sua formação escolar formal. Trabalhou, naquele período, como agricultor - e chegou a ganhar fama como floricultor e colecionador de orquídeas.

0 jovem mineiro chegou a propor a criação de um orquidário no jardim municipal de Juiz de Fora. Entretanto, 0 Presidente da Câmara dos Vereadores de Juiz de Fora, Duarte de Abreu, tinha outros planos - e em 1907 enviou uma carta recomendando a contratação de Hoehne ao Diretor do Museu Nacional do Rio de Janeiro, João Batista Lacerda, com cópia ao engenheiro e naturalista João Barbosa Rodrigues, um proeminente botânico que havia, em meio a uma ampla produção científica, dirigido ao Jardim Botânico de Manaus no final do século XIX. 
Com o aceite da indicação, Hoehne passou a exercer o cargo de jardineiro-chefe do Museu Nacional do Rio de Janeiro: "uma oportunidade para o acesso à biblioteca e o consequente encaminhamento na senda profissional que jamais abandonamos"9. Em pouco tempo, Hoehne tornou-se encarregado e administrador do jardim do Paço Imperial Quinta da Boa Vista, sede da monarquia entre 1822 e 1889 e composto por magníficas edificações, e do Horto Botânico, onde havia instalações para pesquisas e observações vinculadas à Seção de Botânica do Museu Nacional.

0 Museu Nacional, criado em 1818, foi a primeira instituição científica no país - após ter sido a moradia oficial do rei D. João VI. No início do século XX, o Museu reunia um importante acervo bibliográfico e a mais abrangente coleção de espécies vegetais no Brasil. Naquele período, uma geógrafa americana descreveu as atividades dos jardins e parques nacionais e salientou a preocupação precursora de seus dirigentes com a divulgação de conhecimentos sobre a natureza:

A biblioteca do Museu Nacional é enriquecida de ano em ano pela aquisição de obras relevantes em botânica e horticultura, muitas das quais doadas pelo Dr. Barbosa Rodrigues, o qual já teve reconhecimento por seus incansáveis estudos da flora de seu país. Panfletos relacionados ao cultivo e cuidado de plantas são enviados para todo o país e durante o ano de 1906 não somente grandes quantidades de sementes foram enviadas para comunidades agrícolas, como centenas de árvores frutíferas, de sombra e ornamentais foram distribuídas pela administração. Cem mil pessoas visitam o Jardim Botânico anualmente ${ }^{10}$.

Em 1908, o tenente-coronel Cândido Mariano Rondon, que na época vinha organizando as Comissões de Linhas Telegráficas e Estratégicas do Mato Grosso ao Amazonas (CLTEMA), aceitou do professor Alípio Miranda Ribeiro (1874-1939), zoólogo/ictiólogo do Museu Nacional, a indicação de Hoehne como botânico responsável pela coleta, armazenamento e identificação do material vegetal obtido pela Comissão durante suas expedições. A missão científica da Comissão era dividida em três grandes áreas: Zoologia, Botânica e Geologia.

Em 27 de junho de 1908, Hoehne, aos 26 anos, partiu para o Matto Grosso, de onde retornou após um ano e quatro meses. A excursão teve início no Rio de Janeiro e seguiu pela costa até o Uruguai, adentrando o continente pelo Rio da Prata, até chegar ao porto de Corumbá (atual MS). Iniciava-se a participação de Hoehne nas grandes expedições da Comissão Rondon ${ }^{11}$. Após seu retorno e durante 0 ano de 1910, Hoehne passou a organizar, em seu escritório no Museu Nacional, todo o material coletado durante a expedição; pouco depois, publicou uma primeira parte da obra História Natural: Botânica. Ainda no final daquele ano, partiu para uma segunda expedição no âmbito da Comissão, contemplando rotas do Pantanal Norte e da Amazônia Legal (nos atuais estados do Mato Grosso e de Rondônia). A Comissão somente retornaria desta viagem em junho de $1912^{12}$, ano em que Hoehne publicou outras três partes de História Natural: Botânica ${ }^{13}$.

Em fevereiro de 1913, Hoehne foi nomeado chefe do Gabinete de Botânica da Inspetoria de Pesca, do Ministério da Agricultura, deixando o cargo no Museu Nacional. Alípio Miranda Ribeiro, com quem vinha trabalhando na Inspetoria, o auxiliou na criação de uma biblioteca especializada em plantas aquáticas, a partir de uma coleção de livros doados pela viúva de João Barbosa Rodrigues, falecido em 1909. Também foi montado um laboratório de plantas aquáticas. Durante estes estudos, Hoehne recebeu de Rondon um convite para participar de mais uma expedição, desta vez para acompanhar 0 ex-presidente norte-americano Franklin D. Roosevelt.

Após ter perdido a reeleição em seu país, Roosevelt, que havia percorrido o continente africano, planejou uma excursão pelas florestas brasileiras. Um acordo com Rondon permitia a Roosevelt realizar caças em troca de patrocínio para a Comissão. Chamava a atenção do "aventureiro" Roosevelt uma área denominada rio da Dúvida, que conteria, supostamente, uma conexão entre a bacia do Paraguai e a bacia do Médio Purus. Rondon, no entanto, demonstrava já não acreditar em tal lendária possibilidade. A expedição, realizada de novembro 1913 a janeiro de 1914, que chegou a ser relatada por Hoehne ${ }^{14}$, adentrou a bacia dos rios Aripuanã e Madeira - e foi registrada em cinema mudo, com 0 título The River of Doubt.

Como Alípio Miranda de Ribeiro e sua equipe não puderam participar desta expedição, Hoehne e outros dois taxidermistas ficaram encarregados de coletar e registrar a fauna encontrada. Hoehne pôde ainda coletar mais ma- 
teriais e teve a oportunidade de atuar, simultaneamente, como zoólogo no trecho de Corumbá até as imediações do rio Aripuanã, quando abandonou a expedição por considerar que Rondon estava priorizando a participação dos pesquisadores norte-americanos ${ }^{15}$. Em seu livro de memórias, Roosevelt menciona a participação de Hoehne: “Um dos brasileiros membros de nossa equipe, Hoehne, o botânico, era um zoólogo também. Ele me informou que havia notado que mesmo os grandes morcegos comedores de frutas poderiam sugar sangue. De acordo com suas observações, eles não iniciavam a ferida; mas depois de ter sido feita por um dos verdadeiros vampiros, eles poderiam se aproveitar do sangue que escorre e aumentar a injúria"16.

Todavia, Hoehne foi impedido de reassumir o cargo na Inspetoria de Pesca, uma vez que um substituto havia sido convocado durante sua participação na expedição. Diante disso, Candido Rondon, sensibilizado pelo acontecimento, decidiu contratá-lo novamente para uma excursão especial para o estado de Minas Gerais, na qual foram colhidos cotipos de plantas referidas no herbário de Johanes Eugenius Büllow Warming (1941-1924), pesquisador dinamarquês e ex-diretor do Jardim Botânico de Copenhague, que publicara em 1908 no Brasil a obra Lagoa Santa. A viagem foi realizada de setembro de 1915 a janeiro 1916. Mas baixa remuneração e as precárias condições para a realização de pesquisas levaram Hoehne a buscar novas opções de vinculação profissional, como consta em sua autobiografia ${ }^{17}$. Naquele período, Hoehne foi nomeado "membro correspondente" do Museu Nacional e participou, em 1916, da fundação da Sociedade Brasileira de Ciências (em 1921, renomeada para Academia Brasileira de Ciências).

\section{A atuação de Hoehne na Seção de Botânica do Instituto Butantã, 1917-1923}

Em 1917, após o afastamento do cargo na Inspetoria de Pesca do Rio de Janeiro e a atuação nas expedições com Rondon, Hoehne recebeu um convite do Diretor do Serviço Sanitário do Estado de São Paulo, o etnógrafo e político Artur Neiva (1880-1943), para criar um horto com o objetivo de promover o cultivo e aclimatação de plantas tóxicas e medicinais no Instituto Butantã, em São Paulo, como definia a lei $n^{0} 1596$, de 29 de novembro de $1917^{18}$. No ano seguinte, Hoehne foi nomeado botânico do Instituto Butantã, onde passou a chefiar a recém-criada Seção de Botânica. Ele teve êxito em sua reivindicação de fazer com que a Estação Biológica do Alto da Serra do Paranapiacaba, localizada entre São Paulo e São Bernardo do Campo, ficasse subordinada à sua Seção. Naquele ano, viajou pelo litoral paulista em companhia de Artur Neiva, do sanitarista Francisco Salles Gomes Filho e do escritor Monteiro Lobato ${ }^{19}$.

O herbário organizado por Hoehne, que vinha sendo formado desde as expedições da Comissão Rondon, passou a integrar o acervo da Seção de Botânica do Instituto Butantã, que além do herbário, contava com laboratórios de química e fisiologia vegetal. 0 Horto Oswaldo Cruz, administrado pela Seção de Botânica, foi criado com o intuito de promover o cultivo de espécies vegetais com ação vermífuga, entre as quais o quenopódio (Chenopodium album L.), que passou a ser sistematicamente estudado por Hoehne. Através de testes realizados em sua seção, Hoehne demonstrou que a planta também conhecida como ançarinha-branca, de amplo uso popular naquela época, possuía em suas sementes uma substância vermífuga mais eficiente do que qualquer outra espécie exótica até então conhecida, o que acenava para uma descoberta de relevância internacional.

Alguns lotes de medicamentos derivados do quenopódio foram produzidos experimentalmente no Instituto Butantã sob a coordenação de Hoehne, que passou a publicar artigos científicos e de divulgação sobre o tema. 0 interesse pelo uso popular de plantas medicinais o levou a realizar uma pesquisa etnográfica na cidade de São Paulo com a finalidade de catalogar os vegetais utilizados como anti-helmínticos. Ele então passou a pesquisar 0 universo cultural dos raizeiros e vendedores de ervas. A partir de suas observações, Hoehne publicou, em 1920, dois livros: 0 que vendem os hervanários da cidade de São Paulo e Vegetais Antihelminticos ou enumeração dos vegetais empregados na medicina popular ${ }^{20}$. 
Naquele período, o médico imunologista Vital Brazil (1865-1950) havia fundado em Niterói um instituto pesquisa em saúde (atualmente denominado Instituto Vital Brazil) - e em carta de 25 de junho de 1920 convidou Hoehne para atuar como docente de Botânica na Faculdade de Medicina em formação. Entretanto, Hoehne decidiu continuar com o trabalho que vinha desenvolvendo no Horto Oswaldo Cruz do Instituto Butantã.

Em 1921, Hoehne publicou o primeiro fascículo de uma coletânea de estudos taxonômicos, voltada para leigos, Leguminosas Forrageiras Nativas, no qual apresentava uma chave dicotômica específica do gênero Desmodium, conhecido popularmente como carrapicho beiço-de-boi ou feijão de boi, considerada por Hoehne uma alternativa nutricionalmente mais eficiente do que a alfafa tanto para a fenação como para a forragem. No prefácio, ele ressaltou o potencial deste vegetal como forragem na alimentação animal.

Outros fascículos de seus estudos taxonômicos, publicados nos Anexos das Memórias do Instituto Butantã, contemplavam as famílias das orquidáceas, melastomatáceas, convolvuláceas e rubiáceas. 0 uso potencial de cada espécie ali descrita era prontamente indicado, fosse para fins medicinais, paisagísticos, agropecuários, urbanísticos, ecológicos, industriais, residenciais. No fascículo II, que trata das orquídeas, Hoehne denunciou que coletores e comerciantes, naquele início dos anos 1920, em alguns casos, extraíam todas as orquídeas com potencial ornamental de algumas localidades, de tal forma que, mesmo sem dispor de condições minimamente adequadas de transporte e acondicionamento, eliminavam as possibilidades de exploração continuada da atividade ${ }^{21}$.

Em outra obra relevante, publicada em 1922, foi A Flora do Brazil: Recenseamento de 1920, Hoehne fez uma primeira tentativa de organizar a biografia dos principais botânicos que cooperaram para o estudo da flora brasileira ${ }^{22}$. É possível encontrar ali informações sobre a fitofisionomia em diversos biomas de nossa flora indígena, sobre os vegetais úteis cultivados de maior interesse, como cana-de-açúcar, café, mate, tabaco, seringa e cacau; e sobre muitas outras plantas que poderiam ser utilizadas na ornamentação ou que possuíam propriedades tóxicas para o gado. Tratava-se, com efeito, do esboço de um grande projeto científico e intelectual que seria colocado em prática nas décadas seguintes e que viria a ser consolidado em 1941 com a publicação de 0 Jardim Botânico de São Paulo²3.

Pelo Decreto n. ${ }^{\circ} 1.911$ de 29 de dezembro de 1922, a Seção de Botânica, na qual Hoehne era encarregado-chefe, foi transferida para o Museu Paulista - e o Horto Oswaldo Cruz foi extinto para dar lugar a um novo plano de ocupação daquela área do Instituto Butantã.

\section{A mudança para o Museu Paulista, 1923-1928.}

Com a extinção do Horto Oswaldo Cruz, então vinculado ao Instituto Butantã, a Seção de Botânica, incluindo todas as coleções de plantas e materiais de pesquisa reunidos por Hoehne, foi transferida para o Museu Paulista ${ }^{24}$. Em 1924, Hoehne tornou-se membro da National Geographic Society, após um convite que pretendia "inspirar as pessoas a cuidarem do planeta". Este foi um dos primeiros reconhecimentos internacionais de sua carreira científica e atuação institucional e cultural. Com a saída de Hoehne do Instituto Butantã, o Horto Oswaldo Cruz ficou desativado até 1925, quando novamente, no próprio Butantã, houve uma revalorização do trabalho que havia sido desenvolvido por Hoehne em suas dependências.

No período em que a Seção de Botânica esteve subordinada ao Instituto Butantã, Hoehne não somente produziu obras científicas no campo da botânica, mas também um grande número de publicações em jornais, como $A$ forragem verde no inverno (1924), 0 ensino da biologia em nossas escolas (1924), Plantas tóxicas para o gado (1924), Qual o escopo do Serviço Florestal Brasileiro? (1926) e Ciência Agronômica Indígena (1928), todas pelo 0 Estado de São Paulo. Além disso, foi correspondente de jornais como Diário da Noite e Correio Paulistano e de revistas como Chácaras e Quintaes, Estradas de Rodagem e Criador Paulista ${ }^{25}$. Em 1925, atuou diretamente na delimitação da Estação Biológica do Alto da Serra do Paranapiacaba, onde, em 1930, foram construídas as primeiras instalações de pesquisa e um alojamento. 
Hoehne também se dedicou à literatura infanto-juvenil. 0 livro As aventuras do Casaquinha Verde, que corresponde ao volume I da série História e Dramas da Natureza, foi publicado em 1925, ou seja, durante sua breve passagem pelo Museu Paulista. Esse livro conta a história de vida de um beija-flor (no original, Chlorostilbon lucidus; atualmente, Chlorostilbon aurioventris), seu pareamento, o aprendizado de seus filhotes, a confecção dos ninhos com teias de aranha e gravetos; também traz noções de ecologia, como o relato da caçada de uma vespa (Pepsis sp.) para depositar seus ovos no corpo de uma aranha. No final dessa produção ficcional, nota-se que a intenção do autor era denunciar a matança de beija-flores, pois seu couro vinha sendo enviado a ateliês de alta costura em Nova lorque, onde era utilizado na produção de luxuosos chapéus. No texto, os caçadores matavam os beija-flores com maior facilidade justamente quando os mesmos pairavam sobre as orquídeas, que em geral se desenvolviam sob as copas das palmeiras ${ }^{26}$.

\section{Hoehne e a fundação do Instituto Biológico, 1928-1938}

Em 1924, a cafeicultura paulista enfrentava um grave problema de fitossanidade: focos da alarmante broca do café foram identificados em propriedades por todo o Estado. Uma comissão composta por Arthur Neiva e pelo médico sanitarista e entomologista Ângelo Moreira da Costa Lima (1887-1964) foi organizada com a finalidade de pesquisar medidas profiláticas e de controle ao inseto causador de danos aos cafezais. Três anos mais tarde, a comissão deu origem ao Instituto Biológico de Defesa Agrícola e Animal ${ }^{27}$. A Seção de Botânica do Museu Paulista, incluindo todo 0 seu acervo, que vinha sendo reunido por Hoehne desde 1917, foi transferida em 1928 para o recém-criado Instituto Biológico, agora com a denominação Seção de Botânica e Agronomia ${ }^{28}$.

Por outro lado, Hoehne planejava a criação de um jardim botânico nas dependências do Parque Estadual das Fontes do Ipiranga, onde já havia uma área verde reservada para esta finalidade. Naquele contexto, recebeu, em 11 de julho de 1929, o título de doutor honoris causa em Filosofia da Universidade de Goettingen, Alemanha. Logo em seguida, foi publicado, em 1930, o segundo volume da série Histórias e Dramas da Natureza, com o título 0 Jequitibá-rei, também voltado ao público infanto-juvenil, que contava a história de uma árvore, ou seja, todo o seu ciclo vital. Há alusão, de forma didática, a inúmeras relações ecológicas ocorridas durante a vida do exemplar ${ }^{29}$.

Após começar a atuar no Instituto Biológico, Hoehne publicou cartilha A Bracaatinga ou Abaracaatinga (1930), na qual analisou, no gênero Mimosa, as espécies conhecidas como bracatinga, encontradas, sobretudo, nos estados do Paraná e de Santa Catarina, onde seu uso era mais variado e difundido. Hoehne relatou que o Serviço Florestal da Companhia Paulista de Estradas de Ferro teria tentado utilizar a madeira desta espécie para as suas operações, mas esta experimentação, proposta pelo agrônomo e silvicultor Edmundo Navarro de Andrade (1881-1941), não apresentava o potencial de uso esperado $0^{30}$.

Em 1934, o Instituto Biológico de Defesa Agrícola e Animal passou por uma reforma administrativa e recebeu a denominação ainda hoje vigente, Instituto Biológico. Hoehne foi então nomeado primeiro assistente e chefe do Serviço de Botânica e Agronomia. No mesmo ano, começou a publicar, periodicamente, no jornal 0 Estado de São Paulo, um conjunto de artigos para divulgação dos estudos e pesquisas que vinha realizando no Instituto Biológico, o que resultou no total 114 "aulas" até 1938. Esses textos, revistos e ilustrados em 1939, foram reunidos e publicados sob o título Plantas e Substancias Vegetaes Tóxicas e Medicinais. A impressão ficou a cargo do recém-criado Departamento de Botânica do Estado de São Paulo ${ }^{31}$.

Em 1934, Hoehne tornou-se membro fundador e efetivo do Conselho Florestal do Estado de São Paulo, tendo ocupado sua presidência durante vários anos consecutivos ${ }^{32}$. Outras obras foram publicadas nesse período, como 0 segundo volume de Plantas Ornamentais da Flora Brasílica em 1936 e, no ano seguinte, Botânica e Agricultura no Brasil no século XVI , na coleção Brasiliana ${ }^{33}$. 
Em meio à comemoração do vigésimo aniversário da Seção de Botânica e Agronomia (1917-1937), Hoehne envia a tese $A$ Formação de homens ao Primeiro Congresso de Ensino Rural, promovido pela Sociedade Luiz Pereira Barreto, instituição vinculada à defesa educação em medicina e em áreas rurais. 0 parecer dos relatores do congresso sobre 0 seu texto foi o seguinte: "Recomenda o nosso eminente botânico: $\left.1^{\circ}\right)$ Abolição da odiosa proteção de algumas culturas, quando outras são esquecidas e desprezadas; $2^{\circ}$ ) Retalhamento dos latifúndios; $3^{\circ}$ ) A formação de homens sadiamente educados, que não desprezem a técnica mas que, também, estejam imbuídos das mais elevadas forças morais" ${ }^{\prime \prime 34}$.

\section{Hoehne no Instituto de Botânica, 1938-1952}

Pode-se interpretar que, do ponto de vista institucional, Hoehne chegou mais próximo de seu ideal com a criação do Departamento de Botânica do Estado em 1938, uma vez que permitiu o aproveitamento integral do pessoal, do acervo material e do patrimônio reunido até então na Seção de Botânica e Agronomia do Instituto Biológico. Hoehne recebeu o cargo de diretor-superintendente do departamento, o que facilitaria suas atividades e projetos, já que ficou subordinado diretamente ao secretário de Agricultura. Ele chegou a atribuir este avanço a Adhemar de Barros, interventor federal no Estado de São Paulo (de 1938 a 1941) que, após ter conhecido a coleção de espécimes vivos de orquídeas que Hoehne vinha reproduzindo ao longo de toda sua vida, também o apoiou na criação do Jardim Botânico e do Orquidário de São Paulo.

Uma atividade política e cultural de Hoehne se concretizou naquele período, com a fundação da Sociedade Amigos da Flora Brasílica em 21 de setembro de 1939, quando foi celebrada a Festa da Árvore no Jardim Botânico do Estado de São Paulo. A sociedade possuía inicialmente 113 sócios, entre cientistas, políticos, profissionais liberais, agricultores e outros. A organização tinha a finalidade imediata de formar um novo catálogo florístico, e, além disso, buscava a ampliação do debate público sobre a importância da criação de reservas biológicas e das atividades de reflorestamento no país ${ }^{35}$. Hoehne foi um dos idealizadores e sócios fundadores dessa associação com fins ambientais no Brasil e ocupou sua presidência por vários anos ${ }^{36}$.

Em 7 de janeiro de 1942, através do Decreto n. ${ }^{0}$ 12.499, o Departamento de Botânica foi transformado em Instituto de Botânica, cuja Diretoria Hoehne assumiu desde o início - e na qual permaneceu até a sua aposentadoria, em 1952, aos 70 anos. Durante a década em que dirigiu o Instituto de Botânica (1938-1952), Hoehne foi responsável pela publicação de Relatórios Anuais do Instituto de Botânica, nos quais era apresentada sua contabilidade e divulgada sua produção científica e cultural. Assuntos diversos eram trazidos aos leitores: contribuições para o estudo das orquídeas, textos fomentando o reflorestamento artificial e natural, apresentação de pesquisas e premissas etnográficas, estudos sobre a agricultura indígena no Brasil e no continente americano, solenes referências a personalidades como Edmundo Navarro de Andrade e João Barbosa Rodrigues, transcrição de palestras proferidas por membros da Sociedade Amigos da Flora Brasílica e muitos outros temas.

Dois livros de destaque da obra de Hoehne foram publicados em 1944: Arborização Urbana, que reúne uma ampla lista de espécies arbóreas nativas recomendadas para o plantio em áreas urbanas ${ }^{37}$, e Frutas Indígenas, que tinha o objetivo de apresentar as árvores e plantas frutíferas da flora brasileira e estimular sua produção e consumo. Em Plantas Aquáticas, que também foi escrita naquele ano, mas publicada apenas em 1955, apresentou os projetos para a instalação no Jardim Botânico de um hidrofitotério, uma instalação idealizada por Hoehne para cultivo, pesquisa e visitação pública de plantas aquáticas ${ }^{38}$.

Ao longo da década de 1940, Hoehne recebeu diversas distinções honoríficas: Associación Sudamericana de Fitotaxinomistas (Argentina, 1940), Botanical Society of America (EUA, 1941), The Torrey Botanical Club (EUA, 1941); foi ainda indicado como Sócio Honorário da Sociedade Rural Brasileira (1941) e Membro Correspondente del Instituto Equatoriano de Ciências Naturales (Equador, 1941), Membro Correspondente da Sociedade Venezuelana de Ciencias Naturales (1942), membro da American Forestry Association (1943) e da American Society of Plants Taxonomists 
(1945), tornou-se também sócio honorário da Sociedade de Bromélias (California, 1950) e da Sociedade Botânica do México (1951). Isso demonstra como Hoehne, assim como outros cientistas naquele período, procurou vincular sua produção a uma rede internacional de cooperação ${ }^{39}$.

\section{A interação entre Botânica e Ciências Agrárias}

A trajetória profissional de F. C. Hoehne incluiu, como vimos, uma expressiva contribuição na criação e consolidação de algumas das mais importantes instituições científicas do Rio de Janeiro e, principalmente, de São Paulo. Hoehne abordou em suas pesquisas um variado conjunto de questões sobre a relação entre sociedade e natureza, com especial ênfase para o potencial da aplicação da Botânica e das espécies nativas em atividades agrícolas, florestais, pecuárias, urbanísticas e industriais. Amparado por sua vasta pesquisa sobre a flora brasileira, passou a defender a proteção dos remanescentes florestais em uma época de acelerada devastação. Além disso, há em sua obra um conjunto bastante relevante de reflexões e propostas que visavam conciliar o desenvolvimento em curso no país com as peculiaridades ecológicas e culturais das várias regiões brasileiras.

Em Botânica e Agricultura no Brasil no século XVI (1937), uma de suas obras mais divulgadas, Hoehne fez uma ampla revisão de documentos da Biblioteca do Museu Nacional do Rio de Janeiro e identificou as considerações sociais e ecológicas contidas nos legados de Padre Manuel da Nóbrega, José de Anchieta, André Thevet, Jean de Lery, Pero de Magalhães Gandavo, Gabriel Soares de Souza, Frei Vicente do Salvador e Sebastião da Rocha Pitta, entre outros. Esta espécie de tradição, como salientava Hoehne, longe de se constituir como algo útil e aproveitável apenas para cientistas e especialistas, poderia, segundo ele, compor o repertório cultural da sociedade como um todo: "Para um povo de um país que se diz essencialmente agrícola, a apuração da origem e pátria dos vegetais úteis é sempre questão digna de atenção. Ela deve interessar não somente aos cientistas, mas também aos agricultores em geral, por que envolve elementos muitos, com o auxílio dos quais se pode conseguir resolver problemas de genética e de defesa vegetal e animal"40.

Tais observações relacionadas à produção agropecuária somam-se a muitas outras. No capítulo denominado "Algo sobre a pré-história", Hoehne analisa o modo de vida de populações indígenas no período pré-colonial: "Como a distribuição geográfica das plantas úteis está intimamente relacionada com a distribuição do homem sobre a face da terra, é evidente que o seu estudo interessa igualmente a história da raça humana"41. Ele ressaltava a importância de se pensar a história da Botânica de forma articulada com a história da Agricultura, sempre com um sentido prático voltado para a adaptação e aprimoramento técnico e social do uso do solo nos trópicos: “0 pretérito sendo a base do presente, demonstra-nos que este é base e alicerce, quiçá arcabouço do porvir. 0 material juntado pelos que se foram serviu-nos, em parte, para esta obra: ela há de servir também a alguém, senão para aprender ao menos para corrigir"42.

Em 1917, Hoehne deu início a um notável empenho para edificação daquilo que hoje constitui o Instituto de Botânica (lbot), junto à Secretaria do Meio Ambiente do Estado de São Paulo; elaborou o projeto do Jardim Botânico de São Paulo e do Instituto de Botânica, desde sua composição e organização florística até a demarcação das áreas verdes preservadas no Parque das Fontes do Ipiranga, bem como seu arruamento e infraestrutura, visando à realização de pesquisas científicas para a aclimatação de plantas, divulgação de trabalhos produzidos na área de Botânica e Ecologia e à estruturação da Estação Biológica do Alto da Serra do Paranapiacaba ${ }^{43}$.

Há nas publicações de Hoehne entre 1921 a 1951 uma vasta indicação de espécies da flora nativa com potencial de uso, sobretudo na agricultura, na pecuária, no extrativismo florestal, na indústria e na vida cotidiana. Essa perspectiva de identificação e análise do potencial de espécies nativas para Agropecuária e para a Silvicultura, que se inseria em uma certa tradição e que contava com adeptos nas primeiras décadas do século XX, afigurava-se como um elemento central em suas atividades científicas, políticas e culturais, algo presente já em suas primeiras publicações - e que em 1921 era apresentado da seguinte forma: 
Existem espécies indígenas, até hoje inaproveitadas entre nós, que em matéria alimentícia e facilidade de aperfeiçoamento pouco ou nada ficam a dever às espécies dos gêneros exóticos citados. São especialmente as do gênero Meibomia, MOEHR (Desmodium, DESV); Crotalária, L.; Zornia, GMEL; Stylosanthcs, Sw. Arachis, L.; e de outros afins, mais ou menos herbáceas, que poderiam ser aproveitadas com grande vantagem para fornecer não só magnífico pasto verde, mas também o feno para a alimentação do gado em estábulos durante os meses em que difícil se torna a sua manutenção com forragem fresca, livrandonos assim de grande despesa feita anualmente com a importação de forragem estrangeira e contribuindo para a nossa emancipação econômica ${ }^{44}$.

Ou ainda, em uma síntese dessa perspectiva: “Saber quais as espécies que mais vantagem poderiam oferecer e onde encontrar sementes para o ensaio de sua cultura e aperfeiçoamento, eis onde está o X da questão". Sua concepção sobre Botânica não se dissociava de sua ampla aplicação para a produção agrícola, animal e florestal, em uma abordagem que procurava associar as atividades econômicas rurais às peculiaridades ecológicas locais, notadamente com ênfase reiterada sobre a necessidade de popularização desses saberes:

Passemos da palavra à ação: que cada um de nós, que nos interessamos realmente pela grandeza e desenvolvimento da nossa Terra, procure conhecer aquilo que de aproveitável ela encerra, que estude e exponha desse estudo os resultados, de maneira que possam ser utilizados praticamente pelos interessados, eis o que deve substituir as palavras ocas ou vazias com que temos procurado até aqui nos enganar mutuamente ${ }^{45}$.

Em algumas publicações, Hoehne sistematizou conhecimentos acumulados historicamente sobre a flora brasileira e suas formas de utilização, recorrendo para tanto a uma notável revisão bibliográfica e documental que remonta ao século XVI. Em outras publicações, narra suas expedições pelo país e analisa as múltiplas aplicações da Botânica não apenas nas atividades agropecuárias, mas também na arborização urbana e de rodovias, no Urbanismo e no Paisagismo, com grande ênfase para o aproveitamento e a utilização de espécies nativas. Paralelamente, promoveu inúmeras atividades culturais para ampliar a popularização do conhecimento sobre a natureza.

Suas publicações enfatizaram a construção de um conhecimento interativo entre Botânica e as Ciências Agrárias. Publicou também diversos textos sobre Educação, Jardinagem, Paisagismo, Estética, Arquitetura e arborização urbana, entre outros temas, que apontam para uma leitura abrangente e interdisciplinar da cultura brasileira. Desta forma, $\mathrm{Ho}_{\mathrm{O}}$ ehne não descuidou da produção de textos para diferentes públicos sobre Botânica básica (morfologia, sistemática e taxonomia) e avançada (fitogeografia, fitossociologia e fitofisionomia); forneceu relevante contribuição para a Zoologia e a Ecologia; sistematizou registros históricos e observações empíricas sobre o manejo de essências nativas, incluindo a realização de amplas revisões bibliográficas em antropologia e etnografia, especialmente dos trabalhos voltados para a compreensão e a valorização de saberes e práticas agrícolas e extrativistas ancestrais de populações indígenas. Além disso, ao fim de sua vida profissional, Hoehne e seus colaboradores, durante as expedições científicas pelo território nacional, haviam identificado e classificado a maior parte da flora brasileira até então conhecida.

\section{Considerações finais}

Há um amplo conjunto de informações que evidenciam a obra de Hoehne como uma das mais expressivas contribuições à história ambiental e da agricultura no Brasil, bem como da história do pensamento científico sobre a interação entre agricultura e ambiente na primeira metade do século XX, ou seja, no período anterior à modernização agrícola (anos 1950 e 60) e ao movimento (agro) ecológico (anos 1970 e 80). As pesquisas de Hoehne sobre as interações entre Agricultura e Biodiversidade fundamentaram-se em uma vigorosa revisão de saberes científicos e populares constituídos ao longo de toda a história brasileira, em uma perspectiva de continuidade de um amplo conhecimento até 
então acumulado. Suas principais contribuições científicas e discussões conceituais e metodológicas se inserem em um contexto histórico marcado pela construção de algumas das mais importantes instituições de pesquisa até então estabelecidas no país, do qual participou como um grande protagonista.

Pode-se questionar em que medida a obra de Hoehne tem recebido, nos últimos anos, o merecido reconhecimento quando se analisa a história ambiental, agrária e científica brasileira e, especialmente, do Estado de São Paulo. A sistematização e análise da obra de F. C. Hoehne ganha maior significação se levarmos em conta que suas publicações, ainda que parcialmente digitalizadas, encontram-se esgotadas há muitos anos e que, atualmente, apenas parcialmente integram o acervo bibliográfico de universidades e instituições de pesquisa mesmo no Estado de São Paulo. Por outro lado, essas publicações vêm sendo comercializadas - e cada vez mais valorizadas - em sebos espalhados pelo país.

Um aprofundamento nas pesquisas sobre a contribuição científica de Hoehne permite ampliar a compreensão sobre a história do pensamento científico brasileiro, especialmente sobre a relação entre Agricultura e Ambiente. Ao mesmo tempo, há um valioso conjunto de informações, análises e interpretações sobre a biodiversidade brasileira que mantém grande atualidade e relevância para a pesquisa e o ensino sobre diversos aspectos relacionados à sustentabilidade e à biodiversidade em espaços rurais e urbanos.

\section{Notas e Referências bibliográficas}

Ariel de Andrade Molina é bacharel em Agroecologia pela Universidade Federal de São Carlos (UFSCar) e mestrando no Programa de Pós-graduação em Agronomia/ Horticultura da Universidade Estadual Paulista (UNESP-FCA). Bolsista IC/CNPq 2011/2012, bolsista CAPES 2014/2015. E-mail: ariel.molina_agroeco@yahoo.com.br.

Luiz Antonio C. Norder é professor do Programa de Pós-Graduação em Agroecologia e Desenvolvimento Rural (PPGADR) da Universidade Federal de São Carlos (UFSCar).E-mail: luiz.norder@cca.ufscar.br.

1 LOPES, Maria Margaret. O Brasil descobre a pesquisa científica: os museus e as ciências naturais no século XIX. São Paulo: Hucitec, 1997; DANTES, Maria Amélia (Org.). Espaços da Ciência no Brasil: 1800-1930. Rio de Janeiro: Fiocruz, 2001.

2 Uma das exceções a este quadro geral ocorreu no Jardim Botânico do Rio de Janeiro a partir de 1915 durante a gestão de Antônio Pacheco Leão, que se dedicou por vários anos, fundamentalmente, a atividades administrativas, em contraposição aos diretores anteriores, tanto do Jardim Botânico como de outras instituições, que conduziam, simultaneamente, a produção científica e as atividades administrativas, como mostra CASAZZA, Ingrid Fonseca. Um jardim para a Ciência: o Jardim Botânico do Rio de Janeiro (1915-1931). Revista Brasileira de História da Ciência, v. 5, n. 1, p. 101-117, jan/jul. 2012.

3 DUARTE, Regina Horta. A biologia militante: o Museu Nacional, especialização científica, divulgação do conhecimento e práticas políticas no Brasil, 19261945. Belo Horizonte: Editora UFMG, 2010.

4 HEIZER, Alda; VIDEIRA, Antonio Augusto Passos (org). Ciência, civilização e república nos trópicos. Rio de Janeiro: Mauad/Faperj, 2010.

5 SÁ, Dominichi Miranda de; VERGARA, Moema de Rezende. Ciência, natureza e território. Revista Brasileira de História da Ciência. Rio de Janeiro, v. 5, n. 1, p. 8-10, jan.jun. 2012.

6 DEAN, Warren. A ferro e fogo: a história e a devastação da Mata Atlântica. São Paulo: Companhia das Letras, 1996; MARTINEZ, Paulo Henrique. História ambiental paulista: temas, fontes e métodos. São Paulo: Editora SENAC, 2007; PÁDUA, José Augusto. Um sopro de destruição: pensamento político e critica ambiental no Brasil escravista (1786-1888). Rio de Janeiro: Jorge Zahar Editor, 2002; PÁDUA, José Augusto. As bases teóricas da história ambiental. Estudos Avançados, vol. 24, n. 68, p. 81-101, 2010.

$7 \quad$ FRANCO, José Luiz de Andrade; DRUMMOND, José Augusto. Frederico Carlos Hoehne: a atualidade de um pioneiro no campo da proteção à natureza no Brasil. Ambiente e Sociedade, Campinas, v. 8, n. 1, p. 141-166, jan.jun. 2005; DRUMMOND, José Augusto; Frederico Carlos Hoehne: viagem à Araucarilândia. Desenvolvimento e Meio Ambiente, Curitiba, n. 11-12, p. 11-21, jan./dez. 2005.

8 HOEHNE, Frederico Carlos. Relatório Annual do Instituto de Botânica referente ao exercício de 1950. São Paulo: Instituto de Botânica, 1951.

9 HOEHNE, op. cit., 1951, p. 69.

10 WRIGHT, Marie Robinson. The new Brazil: its resources and attractions. Philadelphia: George Barrie and Sons, 1907, p. 162. (Tradução nossa).

11 HOEHNE, op. cit., 1951, p. 74-75; HOEHNE, Frederico Carlos. Relatórios dos trabalhos de Botânica e viagens executados durante os anos de 1908 e 1909 : Anexo n. 4, apresentado ao Sr. Ten. Col. de Eng. Cândido Mariano da Silva Rondon, Chefe da Comissão. Publicação n. 28. Rio de Janeiro: Comissão de Linhas Telegráficas Estratégicas de Mato Grosso ao Amazonas, 1916.

12 HOEHNE, op. cit., 1951, p. 74.

13 HOEHNE, op. cit., 1951, p. 108; HOEHNE, Frederico Carlos. História Natural: Botânica. Parte Il. Rio de Janeiro: Melhoramentos, 1912

14 HOEHNE, Frederico Carlos. Relatório apresentado ao Sr. Cel. Eng. Candido Mariano da Silva Rondon, Chefe da Comissão Brasileira. Anexo 2: Botânica, Expedição Scientifica Roosevelt-Rondon. Rio de Janeiro: Museu Nacional, 1914, 81 p. e 20 pranchas botânicas.

15 DRUMMOND, José Augusto. Roosevelt e Rondon desvendam um rio amazônico. História, Ciências, Saúde - Manguinhos, Rio de Janeiro, v. 17, n. 3 , 
p. 849-854, jul./set. 2010

16 ROOSEVELT, Franklin Delano. Through the Brazilian wilderness. New York: C. Scribner's Sons, 1914. (Tradução nossa)

17 HOEHNE, op. cit., 1951, p. 7; 146.

18 HOEHNE, Frederico Carlos. Resenha histórica para a comemoração do vigésimo aniversário da Seção de Botânica e Agronomia. São Paulo: Instituto Biológico de São Paulo, 1937a; BENCHIMOL, Jaime Larry; TEIXEIRA, Luiz Antonio. Cobras, lagartos e outros bichos: uma história comparada dos institutos Oswaldo Cruz e Butantã. Rio de Janeiro: Ed. UFRJ, 1993.

19 HOEHNE, Frederico Carlos. Álbum da Seção de Botânica do Museu Paulista. São Paulo: Museu Paulista, 1925a, p. 8.

20 HOEHNE, Frederico Carlos. O que vendem os hervanários da cidade de São Paulo. São Paulo: Serviço Sanitário do Estado, 1920; HOEHNE, Frederico Carlos. Vegetais antihelminticos ou enumeração dos vegetais empregados na medicina popular. São Paulo: Instituto Butantã, 1920.

21 HOEHNE, Frederico Carlos. Anexos das memórias do Instituto Butantan: Seção de Botânica. Vol. 1, fasc. II. São Paulo: Melhoramentos, 1921 , p. 3.

22 HOEHNE, Frederico Carlos. Flora do Brazil: recenseamento de 1920. Rio de Janeiro: Diretoria Geral de Estatística. Ministério da Agricultura, Indústria e Comércio, 1922.

23 HOEHNE, Frederico Carlos. O Jardim Botânico de São Paulo. São Paulo: Instituto de Botânica, 1941.

24 HOEHNE, op. cit., 1925a; HOEHNE, op. cit., 1937a.

25 HOEHNE, op. cit., 1951.

26 HOEHNE, Frederico Carlos. As aventuras do casaquinha-verde. São Paulo: Livraria Liberdade, 1925b. (Série Dramas e Histórias da Natureza, 1).

27 RIBEIRO, Maria Alice. História, ciência e tecnologia: 70 anos do Instituto Biológico de São Paulo na defesa da Agricultura, 1927-1997. São Paulo: Instituto Biológico, 1997.

28 HOEHNE, op. cit., 1937.

29 HOEHNE, Frederico Carlos. 0 jequitibá-rei. São Paulo: Livraria Liberdade, 1930. (Série Dramas e Histórias da Natureza, 2).

30 HOEHNE, Frederico Carlos. A bracaatinga ou abaracaatinga. São Paulo: Instituto Biológico; Secretaria da Agricultura, Indústria e Comercio do Estado de São Paulo, 1930.

31 HOEHNE, Frederico Carlos. Plantas e substâncias vegetais tóxicas e medicinais: uma coletânea de 114 aulas publicadas no jornal 0 Estado de São Paulo de 1934 a 1938. Edição ilustrada e revista. São Paulo: Instituto de Botânica, 1939.

32 HOEHNE, op. cit., 1951, p. 147.

33 HOEHNE, Frederico Carlos. Plantas ornamentais da Flora Brasílica e o seu papel como fatores de salubridade pública, da estética urbana e artes decorativas nacionais. Coleção de Separatas do Boletim de Agricultura, n. I. São Paulo: Instituto Biológico, 1930; HOEHNE, Frederico Carlos. Botânica no Brasil no século XIV: pesquisas e contribuições. São Paulo: Editora Nacional, 1937b.

8034 HOEHNE, op. cit., 1951, p. 150.

35 DEAN, op. cit., 1996, p. 275.

36 HOEHNE, op. cit., 1951, p. 147

37 HOEHNE, Frederico Carlos. Arborização urbana: fruto da observação e experiência de longos anos, oferecidos aos senhores Prefeitos. Separata do Relatório Anual do Instituto de Botânica referente a 1943. São Paulo: Instituto de Botânica, 1944.

38 HOEHNE, Frederico Carlos. Plantas Aquáticas. São Paulo: Instituto de Botânica, 1955; VISNADI, Sandra Regina, SHIRASUNA, Regina Tomoko e COSTA, Janaina Pinheiro. Hidrofitotério. 20 Reunião Anual do Instituto de Botânica. São Paulo, de 25 a 29 de novembro de 2013.

39 Ver, por exemplo, DUARTE, Regina Horta. Coleções de aranhas, redes científicas e política: a teia da vida de Cândido de Mello Leitão (1886-1948). Boletim do Museu Paraense Emílio Goeldi. Ciências Humanas. Belém, vol. 5, n. 2, p. 417-433, maio-ago. 2010.

40 HOEHNE, op. cit., 1937a, p. 12.

41 Ibidem.

42 HOEHNE, op. cit., 1937a, p. 13

43 HOEHNE, op. cit., 1925b; HOEHNE, op. cit., 1951; HOEHNE, Frederico Carlos. Relatório Anual do Instituto referente ao exercício de 1942. São Paulo: Instituto de Botânica, 1943; RIBEIRO, op. cit., 1997; ROCHA, Yuri Tavares; CAVALHEIRO, Felisberto. Aspectos históricos do Jardim Botânico de São Paulo. Revista Brasileira de Botânica, São Paulo, v. 24, n. 4 (suplemento), p. 577-586, dez. 2001; FIGUEIRÔA, Silvia Fernanda de Mendonça. Mundialização da ciência e respostas locais: sobre a institucionalização das ciências naturais no Brasil (de fins do século XVIII à transição ao século XX). Asclepio, Madrid, v. 50, n. 2, p. 107-123, 1998.

44 HOEHNE, Frederico Carlos. Anexos das memórias do Instituto Butantan. Seção de Botânica, v. 1, fasc. 1: Leguminosas forrageiras do Brasil. São Paulo: Instituto Butantã, 1921, p. 5.

45 HOEHNE, op. cit., 1965, p. 5.

[Recebido em Julho de 2013. Aceito para publicação em Abril de 2014] 